\title{
Circular external fixation in the management of tibial plateau fractures in patients over the age of 55 years
}

\author{
Marais LC ${ }^{1}$, Ferreira $\mathrm{N}^{2}$ \\ PhD; Department of Orthopaedics, Grey's Hospital, School of Clinical Medicine, University of KwaZulu-Natal, Pietermaritzburg, 3201, South Africa \\ 2 PhD; Department of Orthopaedics, Tygerberg Hospital, University of Stellenbosch, Cape Town, 7505, South Africa
}

Corresponding author: Dr Leonard C Marais, Department of Orthopaedics, School of Clinical Medicine, Grey's Hospital, Pietermaritzburg, South Africa; email: marais|@ukzn.ac.za; tel: +2733 89734

\begin{abstract}
Introduction: Tibial plateau fractures in the elderly pose significant treatment challenges because of coexisting medical problems, pre-existing degenerative joint disease and osteoporosis. While several studies have reported promising results with the use of circular external fixation, little data is available on its use in older patients. This study aims to compare the complications and union rate of circular external fixation in patients over the age of 55 years with that achieved in younger patients.

Materials and methods: We retrospectively reviewed all patients treated with circular external fixation over a six-year period. Patients were divided in two groups: Group 1 consisted of patients under the age of 55 years and Group 2 of patients 55 years and older. Group 1 consisted of 63 cases (mean age 37.2 \pm 9.1 years and Group 2 of 16 cases (mean age $60.2 \pm 5.8$ years). Apart from the patient age, there was no significant difference between the two groups in terms of demographics, mechanism of injury ( $p$-value $=0.9$ ) or the prevalence of polytrauma $(p=1.0)$.

Results: At a mean follow-up of $19 \pm 6.2$ months all but two of the fractures had united. The mean overall duration of external fixation was $20.2 \pm 8.2$ weeks, with a slightly longer mean time-in-frame in Group 1 (20.9 \pm 1.1 weeks) in comparison to Group 2 $(17.8 \pm 1.4$ weeks, $p=0.1)$. Complications occurred more frequently in patients over the age of 55 years $(56 \%$ vs $37 \%$, $\mathrm{p}$-value $=0.2)$. Loss of reduction also occurred more frequently in patients over 55 years $(19 \%)$, compared to patients younger than 55 years $(6 \%)(p=0.1)$.

Conclusion: Circular external fixation may be a viable treatment option in patients over the age 55 years who sustain highenergy tibial plateau fractures associated with significant soft tissue compromise. No significant difference was found in terms of the union rate or the development of complications when compared to younger patients.
\end{abstract}

Level of evidence: Level 3

Key words: tibial plateau, fracture, circular fixator, external fixation, llizarov, osteoporosis, geriatric, elderly

Citation: Marais LC, Ferreira N. Circular external fixation in the management of tibial plateau fractures in patients over the age of 55 years. SA Orthop J 2018;17(1):35-40. http://dx.doi.org/10.17159/2309-8309/2018/v17n1a5

Editor: Prof Anton Schepers, University of the Witwatersrand

Received: November 2016 Accepted: March 2017 Published: March 2018

Copyright: () 2018 Marais LC, et al. This is an open-access article distributed under the terms of the Creative Commons Attribution Licence, which permits unrestricted use, distribution and reproduction in any medium, provided the original author and source are credited.

Funding: No funding was received for this study.

Conflict of interest: The authors declare they have no conflicts of interest that are directly or indirectly related to the research. 


\section{Introduction}

Tibial plateau fractures are complex injuries that affect a major weight-bearing joint and are frequently associated with significant compromise of the surrounding soft tissue. ${ }^{1}$ At time of injury a large amount of energy is transferred to the thin layer of soft tissue overlying the proximal tibia. As a result, this soft tissue envelope is often intolerant of extensive dissection and this has significant implications for the surgical management of the underlying bony injury. ${ }^{2}$

The management of tibial plateau fractures is difficult and may be associated with complications such as knee stiffness, deep infection, post-traumatic arthritis, malunion and non-union. ${ }^{3}$ Treatment options include circular or hybrid external fixation and internal fixation, with either a single lateral locking plate or dual medial and lateral plates. While open reduction and internal fixation of tibial plateau remains a popular treatment option, it carries the risk of wound complications which can lead to deep sepsis and chronic osteomyelitis in approximately $10-20 \%$ of cases. ${ }^{4-6}$ Heightened awareness of the importance of soft tissue management has led to the development of percutaneous reduction techniques and minimally invasive plate osteosynthesis (MIPO), which aims to minimise these risks. ${ }^{7}$ Circular fixation has also emerged as a useful treatment option in high-energy injuries where the injured soft tissue envelope often precludes open reduction and internal fixation. ${ }^{8}$

Tibial plateau fractures in the elderly poses some additional challenges because of

coexisting medical problems, pre-existing degenerative joint disease and osteoporosis. ${ }^{9}$ Bone mineral density (BMD) is significantly decreased after the age of 60 years in female patients. ${ }^{10}$ Quantitative computed tomography analysis has revealed that the BMD of the tibial plateau is lowest in the central and antero-medial regions and highest in the postero-medial or postero-lateral regions. ${ }^{10}$ This reduction in BMD results in an increased risk of re-displacement of fractures, which may be as high as $79 \%$ in patients over the age of $60 .{ }^{11}$

While several studies have reported promising results with the use of circular external fixation, little data is available on its use in the elderly. ${ }^{1,2,8}$ In the elderly hybrid external fixation has been reported to deliver inferior results in comparison to internal fixation. ${ }^{9}$ This study aims to compare the complication and union rate of conventional circular external fixation in patients over the age of 55 years with that achieved in younger patients. Ethical approval was obtained from our institution's ethics review board prior to commencement of the study.

\section{Patients and methods}

We retrospectively reviewed all patients with tibial plateau fractures treated with circular external fixation at our institution between June 2009 and June 2015. Eligible patients were identified from a prospectively gathered database. All patients treated with circular external fixation for a tibial plateau fracture were included in the study. Patients treated with different fixation techniques, pathological fractures and follow-up of less than 12 months were excluded. For the purposes of this study patients were divided in two groups: Group 1 consisted of patients under the age of 55 years and Group 2 of patients 55 years and older. The subjects' charts were reviewed and data extracted in order to describe the patient demographics, number and nature of surgical procedures performed, time to union and, finally, the complications that occurred. Classification of the fracture and soft tissue injury, time to union, complications and range of knee motion were also documented. Isolated tibial plateau fractures were classified according to the Schatzker classification system. ${ }^{12}$ Fracture dislocation involving the tibial plateau were classified according to the Hohl and Moore classification system. ${ }^{13}$ Soft tissue injury was classified as described by Oestern and Tscherne. ${ }^{14}$ Pin site infections were graded according to the Checketts and Otterburn classification. ${ }^{15}$

The definitive surgical procedure was performed once CT imaging was completed. The condition of the soft tissue envelope did not influence the timing of definitive surgery. The surgical technique included closed or limited open, indirect reduction through a $2 \mathrm{~cm}$ midline incision. After joint line alignment was achieved, a single $6.5 \mathrm{~mm}$ cannulated screw was inserted from lateral, into the subchondral bone (Figure 1). No bone graft was used. Fixation was completed with application of a four-ring circular external fixator. Both llizarov (Smith \& Nephew, Memphis, TN) and TrueLok (Orthofix, Verona, Italy) fixators were used. Frame design and fixation followed the technique previously described. ${ }^{2}$

Post-operative rehabilitation commenced on day 1 after definitive fixation. Early knee range of motion exercises was followed by weight bearing as pain allowed. Pin site dressings were left undisturbed for the first seven days following the procedure. After this period, the dressings were removed and twice daily pin site cleaning, with chlorhexidine-alcohol solution, were commenced. Initially all patients were followed up at twoweekly intervals at our outpatient department. The intervals were extended to four-weekly once a robust rehabilitation programme and pin tract care regimen was established. Particular attention was paid to weight bearing mobilisation, functional rehabilitation and normalisation of gait pattern in order to promote recovery and bony union. Follow-up radiographs, the progress with rehabilitation and the occurrence of any complications were documented at each clinic visit.

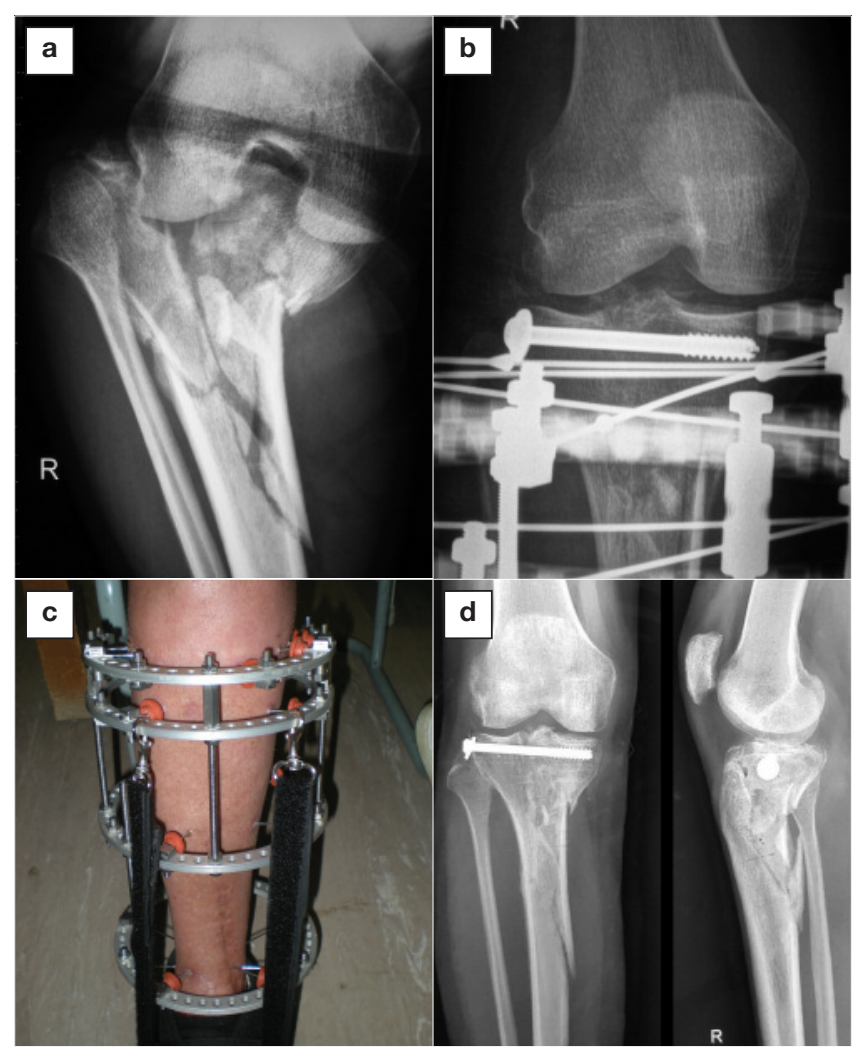

Figure 1. Clinical and X-ray images of a 62-year-old female patient with a Schatzker VI tibial plateau fracture. Pre-operative X-rays show highly comminuted fracture (a). Fracture fixation with a $6.5 \mathrm{~mm}$ cannulated screw and fine-wire circular fixator $(b, c)$. X-ray following removal of external fixation (d). 
Union was considered as the presence of combination of fracture consolidation in at least three cortices and painless weight bearing. Malunion was defined as radiographic angulation of more than 10 degrees in any plane.

Statistical analysis was performed using Stata 13.0 (StataCorp. College Station, Texas). Continuous variables were reported as mean $( \pm S D$ ) or median (with interquartile range) and categorical variables as number and percentages, unless otherwise stated. Differences in continuous variables were compared with the use of the unpaired t-test. The chi-square test was used for categorical data. All tests were two-sided, and the level of significance was set at $\mathrm{p}<0.05$. For the purposes of optimal sample size calculation, a power of $80 \%$ was selected.

\section{Results}

We identified 84 fractures, in 80 patients, that were treated by circular external fixation from the prospectively kept database. Five patients were excluded from the study. Four cases had less than 12 months' follow-up and one patient was lost to followup (Figure 2). Seventy-nine patients, with a mean follow-up of $19.4 \pm 6.2$ months, were included in the analysis. The mean age was 41.8 years (range 21-73 years). The demographic and clinical characteristics of the two groups are provided in Table I. Group 1 consisted of 63 cases below the age of 55 years (mean age $37.2 \pm 9.1$ years) and Group 2 of 16 cases that were 55 years or older (mean age $60.2 \pm 5.8$ years). Apart from the patient age, there was no significant difference between the two groups in term of demographics, mechanism of injury ( $p$-value $=0.9$ ) or the prevalence of polytrauma $(\mathrm{p}=1.0)$. The majority of fractures $(58 \%)$ were sustained in road traffic accidents and $29 \%$ of all patients sustained multiple injuries. Notably, 18 patients were found to be HIV positive (Group 1=17 and Group 2=1, p=0.1) with a mean CD4 count of 389 cells $/ \mathrm{mm}^{3}$.

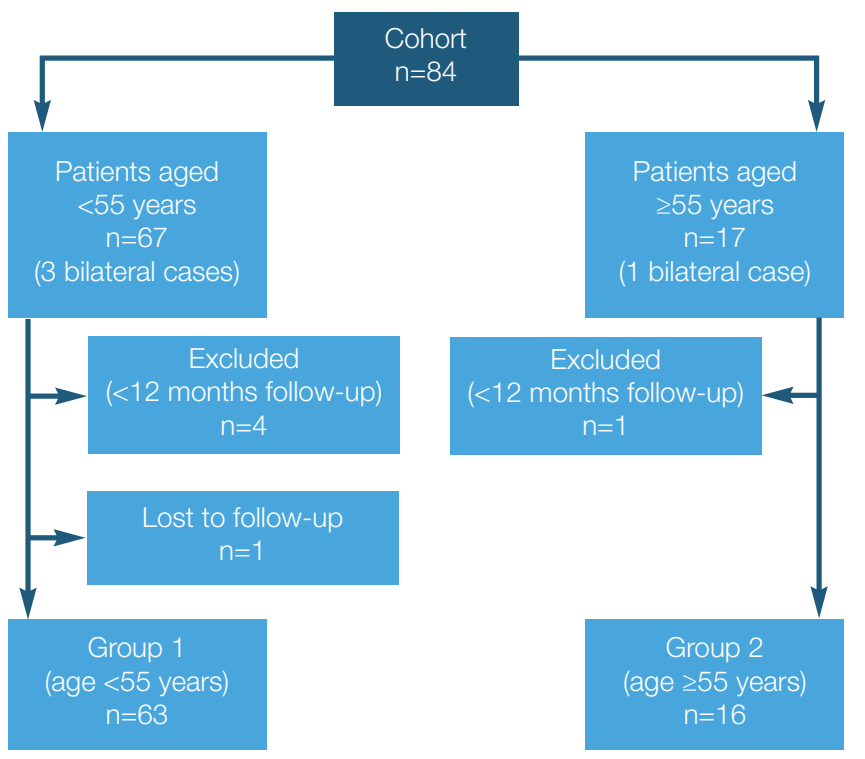

Figure 2. Flow chart of patient population

Table I: Demographic and baseline clinical characteristics of the cohort subdivided into Group 1 (cases under the age of 55 years) and Group 2 (over the age of 55 years)

\begin{tabular}{|c|c|c|c|c|}
\hline & $\begin{array}{l}\text { Overall } \\
\text { ( } N=79)\end{array}$ & $\begin{array}{c}\text { Group } 1 \\
\text { Age }<55 \text { years } \\
(\mathrm{N}=63)\end{array}$ & $\begin{array}{c}\text { Group } 2 \\
\text { Age } \geq 55 \text { years } \\
(N=16)\end{array}$ & p-value ${ }^{b}$ \\
\hline $\mathrm{Age}^{\mathrm{a}}$ & $41.8 \pm 12.5$ & $37.2 \pm 9.1$ & $60.2 \pm 5.8$ & $<0.001$ \\
\hline Male sex (\%) & $52(66)$ & $41(65)$ & $11(69)$ & 1.00 \\
\hline Diabetes (\%) & $3(4)$ & $1(2)$ & $2(13)$ & 0.1 \\
\hline Smoking (\%) & $14(18)$ & $14(22)$ & $0(0)$ & 0.06 \\
\hline HIV (\%) & $18(23)$ & $17(27)$ & $1(6)$ & 0.1 \\
\hline Mechanism of injury & & & & 0.9 \\
\hline $\operatorname{MVA}^{c}(\%)$ & $26(33)$ & $21(33)$ & $5(31)$ & \\
\hline PVA $^{d}(\%)$ & $20(25)$ & $15(24)$ & $5(31)$ & \\
\hline Motorcycle accident (\%) & $5(6)$ & $5(8)$ & $0(0)$ & \\
\hline Fall (\%) & $23(29)$ & $17(27)$ & $6(38)$ & \\
\hline Assault (\%) & $2(3)$ & $2(3)$ & $0(0)$ & \\
\hline Sport (\%) & $2(3)$ & $2(3)$ & $0(0)$ & \\
\hline Bilateral fractures (\%) & $8(10$ & $6(10)$ & $2(13)$ & 0.6 \\
\hline Segmental fracturese (\%) & $5(6)$ & $4(6)$ & $1(6)$ & 1.0 \\
\hline Open fractures (\%) & $11(14)$ & $10(16)$ & $1(6)$ & 0.4 \\
\hline Polytrauma (\%) & $23(29)$ & $18(29)$ & $5(31)$ & 1.0 \\
\hline Fracture classification ${ }^{\dagger}$ & & & & 0.4 \\
\hline Schatzker II (\%) & $2(3)$ & $1(2)$ & $1(6)$ & \\
\hline Schatzker IV (\%) & $3(6)$ & $3(5)$ & $0(0)$ & \\
\hline Schatzker V (\%) & $12(15)$ & $11(17)$ & $1(6)$ & \\
\hline Schatzker VI (\%) & $58(73)$ & $44(70)$ & $14(88)$ & \\
\hline Fracture-dislocation (\%) & $4(5)$ & $4(6)$ & $0(0)$ & \\
\hline Soft tissue classification & & & & 0.5 \\
\hline Tscherne 0 (\%) & $2(3)$ & $2(3)$ & $0(0)$ & \\
\hline Tscherne 1 (\%) & $9(11)$ & $7(11)$ & $2(13)$ & \\
\hline Tscherne 2 (\%) & $26(33)$ & $18(29)$ & $8(50)$ & \\
\hline Tscherne 3 (\%) & $29(37)$ & $25(40)$ & $6(37)$ & \\
\hline
\end{tabular}

a Mean \pm standard deviation [SD]; b Statistical comparison of Group 1 and $2 ;{ }^{~}$ Motor vehicle accident; ${ }^{\text {d }}$ Pedestrian vehicle accident; ${ }^{~}$ Plateau fracture in combination with ipsilateral tibial shaft or plafond fracture; ${ }^{\dagger}$ Schatzker classification system 
Table II: Treatment and complications of the cohort subdivided into Group 1 (cases under the age of 55 years) and Group 2 (over the age of 55 years)

\begin{tabular}{|c|c|c|c|c|}
\hline & $\begin{array}{l}\text { Overall } \\
(\mathrm{N}=79)\end{array}$ & $\begin{array}{c}\text { Group } 1 \\
\text { Age }<55 \text { years } \\
(\mathrm{N}=63)\end{array}$ & $\begin{array}{c}\text { Group } 2 \\
\text { Age } \geq 55 \text { years } \\
(N=16)\end{array}$ & $p$-value ${ }^{b}$ \\
\hline \multicolumn{5}{|l|}{ Treatment } \\
\hline Truelok circular fixator & 36 & 28 & 8 & \multirow{4}{*}{0.2} \\
\hline llizarov circular fixator & 39 & 33 & 6 & \\
\hline Taylor spatial frame & 3 & 2 & 1 & \\
\hline TLHex fixator & 1 & 0 & 1 & \\
\hline Cannulated screw & 64 & 50 & 14 & 0.7 \\
\hline Cross-knee extension & 14 & 10 & 4 & 0.5 \\
\hline Additional surgery & 2 & 2 & 0 & 1.0 \\
\hline Follow-upa (months) & $19.4 \pm 6.2$ & $19.5 \pm 0.8$ & $18.6 \pm 1.5$ & 0.5 \\
\hline Time in frame (weeks) & $20.2 \pm 8.2$ & $20.9 \pm 1.1$ & $17.8 \pm 1.4$ & 0.1 \\
\hline Complications (\%) & $22(41)$ & $23(37)$ & $9(56)$ & 0.2 \\
\hline Pin-tract sepsis (\%) & $14(18)$ & $10(16)$ & $4(25)$ & 0.5 \\
\hline Loss of reduction (\%) & $7(9)$ & $4(6)$ & $3(19)$ & 0.1 \\
\hline Malunion (\%) & $7(9)$ & $5(8)$ & $2(13)$ & 0.6 \\
\hline Joint contracture & $2(3)$ & $2(3)$ & $0(0)$ & 1.0 \\
\hline Non-union & $2(3)$ & $2(3)$ & $0(0)$ & 1.0 \\
\hline Prominent hardware & $1(1)$ & $1(2)$ & $0(0)$ & 1.0 \\
\hline
\end{tabular}

a Mean \pm Standard deviation (SD); ${ }^{\text {} ~ S t a t i s t i c a l ~ c o m p a r i s o n ~ o f ~ G r o u p ~} 1$ and 2

Furthermore, 22\% of patients in Group 1 were cigarette smokers compared to none in Group 2 ( $p$-value $=0.06$ ).

Overall, $88 \%$ of fractures were classified as bicondylar in nature (Schatzker V or VI) and there was no significant difference in the classification of the fracture type between the two groups $(p=0.4)$. The majority of fractures, 70\% in Group 1 and 88\% in Group 2, were classified as Schatzker type VI fractures. Few fractures were unicondylar in nature, $7 \%$ and 6\% in Group 1 and 2 respectively. Significant soft tissue injury (Tscherne class $\geq 2$ ) was present in the $69 \%$ of cases in Group 1 and $87 \%$ of cases in Group 2 (p-value $=0.5)$. Fourteen per cent of all fractures were classified as open (Group 1=16\% and Group 2=6\%, p=0.4).

At a mean follow-up of 19 months (standard deviation $[S D]=6.2$ ) all but two of the fractures had united. The mean overall duration of external fixation was $20.2 \pm 8.2$ weeks, with a slighter longer mean time-in-frame in Group 1 (20.9 \pm 1.1 weeks) in comparison to Group $2(17.8 \pm 1.4$ weeks, $p=0.1)$. There was no significant difference in the type of fixator used $(p=0.2)$, the addition of cannulated screw fixation ( $p=0.7$ ) or the need for cross-knee extension of the external fixator $(\mathrm{p}=0.5)$ (Table I). Three patients in Group 1, compared to none in Group 2, required an additional surgical procedure. In one patient, with a delayed union, a fibula osteotomy was performed which resulted in successful union. Bone graft and locked plate fixation was performed in the second patient for a non-union of a highly comminuted fracture. An iliac crest bone graft procedure was performed in the final patient who sustained a Gustilo-Anderson grade IIIB open fracture. Despite the autogenous bone graft a non-union occurred, at the metadiaphyseal component of the fracture, in this patient. Complications occurred more frequently in patients over the age of 55 years (56\% vs $37 \%$, p-value $=0.2)$. Overall, pin-tract sepsis was the most common complication encountered (18\%) and there was no significant difference between the two groups $(p=0.5)$. Loss of reduction occurred more frequently in patients over 55 years (19\%), compared to patients younger than 55 years $(6 \%)(p=0.1)$. Malunion occurred in 13\% of patient in Group 2 compared to $8 \%$ in Group 1 ( $p=0.6)$. Joint contracture, non-union and prominent hardware occurred infrequently, and only in patients under the age of 55 years. None of the patients required total knee replacement during the follow-up period.

\section{Discussion}

There are several unique characteristics of tibial plateau fractures in the elderly. The most common fracture pattern is Schatzker type II fractures, followed by bicondylar fractures (Schatzker type $V$ and VI). ${ }^{16,17}$ The Schatzker classification is, however, not necessarily predictive of the clinical outcome in patients over the age of 55 years. ${ }^{9}$ Furthermore, there appears to be no correlation between the radiological and clinical outcome of treatment. ${ }^{9,12}$ While radiographic progression of osteoarthrosis occurs in up to $60 \%$ of patients, less than $10 \%$ of patients go on to require total knee replacement. ${ }^{9}$ Su et al. found that the need for arthroplasty becomes evident relatively early and total knee replacements were performed at an average of one year after the injury. ${ }^{9}$ Finally, the incidence of associated knee ligament injuries is also lower in the elderly, approximately $3 \%$, compared to $20-25 \%$ in younger patients. ${ }^{16,18}$

In comparison to younger patients, the outcome of tibial plateau fractures in patients over the age of 40 years is associated with poorer standardised health and disability ratings. ${ }^{19}$ Schwartsman and co-workers drew attention to the problems related to patient self-assessment of treatment outcome and concluded that tibial plateau fractures in patients over the age of 50 years is likely to have an unsatisfactory objective outcome, even in the hands of experienced surgeons, regardless of the treatment method. ${ }^{20}$ Several treatment options have been explored in older patients, including plating, nailing, minimally invasive osteosynthesis and total knee arthroplasty. Satisfactory clinical outcomes have been reported in 70-90\% of elderly patients treated with internal fixation using non-locking plates (Table III).9,16,17,21 While the results of standard plating appears uniformly good, the majority of fractures in these studies were simple fracture patterns with relatively few Schatzker type VI fractures. Frattini et al. found that satisfactory results were obtained in only $53 \%$ of patients with complex fracture patterns, compared to $90 \%$ in the simple fracture pattern group. ${ }^{17}$ Furthermore satisfactory radiological results were achieved in only $32 \%$ of complex fractures. Locking plates offer several potential advantages; however, limited data is available on their use in elderly patients alone. Shimizu et al. reported satisfactory results in $85 \%$ of patients over the age of 65 years, 


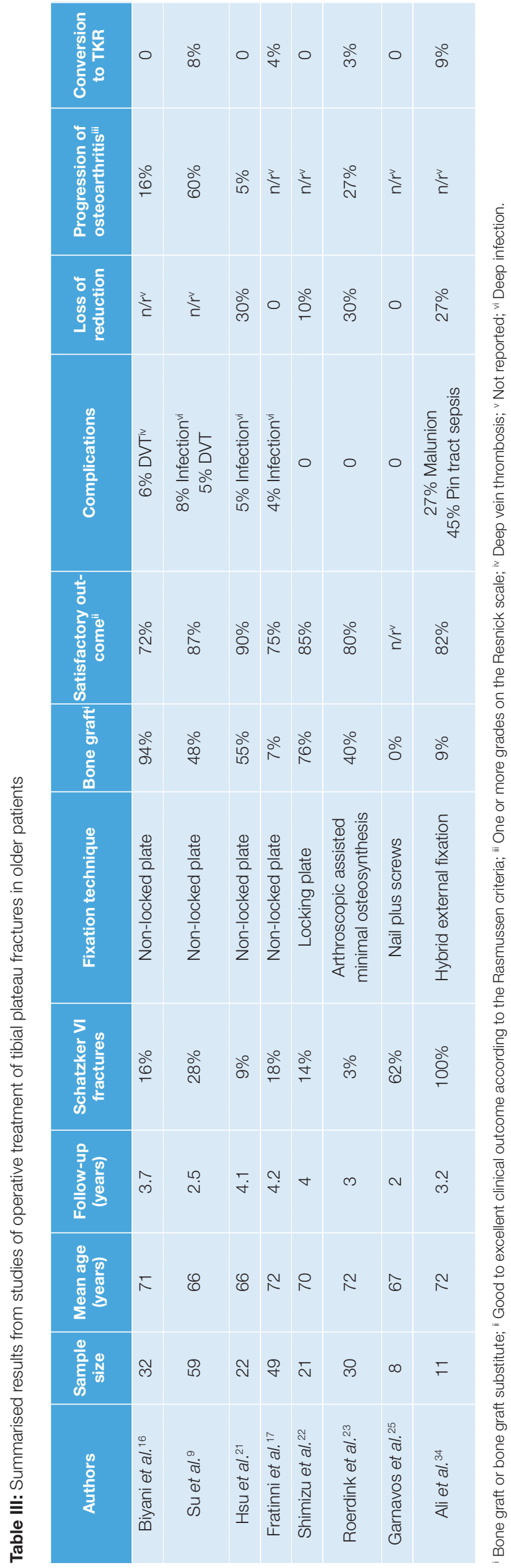

although their series included only three Schatzker type VI fractures. ${ }^{22}$ Novel treatment options have also been explored. Roerdink and co-workers reported good to excellent results in 30 fractures (only one of which was a Schatzker VI) in patients older than 55 treated by arthroscopically assisted minimal osteosynthesis, despite recurrence of displacement in $30 \%$ of cases. ${ }^{23}$ Pizanis et al. utilised balloon tibiaplasty to good effect in five patients aged $44-88$ years with Schatzker type II or III fractures. ${ }^{24}$ Intramedullary nailing in conjunction with inter-fragmentary screw fixation has recently been shown to be a viable option for certain selected cases without significant impaction. ${ }^{25}$ Internal fixation combined with primary arthroplasty has been described as technically challenging, but may be an option in certain complex cases with severe fracture comminution, osteoporosis or pre-existing osteoarthritis. ${ }^{26,27}$

Following some initial enthusiasm for hybrid external fixation in the management of peri-articular fractures, the use of these devices has significantly decreased. Hybrid fixators combine beam loading through tensioned fine wires on a single ring that is attached to a canter-level loading monolateral fixator. The resultant fixator exhibited decreased stiffness at higher loads and less axial and bending stiffness when compared to traditional llizarov circular external fixators. ${ }^{28,29}$ This led to unwanted motion and the fracture site with resultant loss of reduction, non-union and increased pin-site infection rates. ${ }^{30-34}$ Conventional circular external fixation, however, has recently emerged as a viable treatment alternative for bicondylar plateau fractures. ${ }^{8}$ These fixators use beam loading through the entire span of the fixator that results in symmetrical loading of the fracture site. ${ }^{35}$ Multiple pretensioned wires on the proximal ring can be configured to provide uniform support for the tibial plateau articular surface in a custom raft-construct that is tailored to each individual fracture pattern. Biomechanical analysis also demonstrated that the use of four tensioned olive wires combined with a single lag screw provided adequate stability when compared to dual plating. ${ }^{28}$

The aim of this study was to compare the complication and union rate of tibial plateau fractures treated by circular external fixation in patients older than 55 years with that achieved in younger patients. While we would like to believe that a 55-year-old person should not be classified as elderly, we used this figure as it is in line with previously published reports. ${ }^{9,20}$ No significant difference was found in terms of the union rate or the development of complications. The duration of external fixation was marginally shorter in patients over the age of 55 years. While loss of reduction and malunion was encountered more frequently in patients over the age of 55 years, the difference was not statistically significant. It should however be noted that the cohort comprised mainly cases with high-energy fracture patterns and/or a compromised soft-tissue envelope. In fact, $88 \%$ of patients older than 55 years had Schatzker type IV fractures. These results should therefore not be extrapolated to tibial plateau fractures in general.

There are several shortcomings to this study. First, the number of cases in Group 2 is small and the event rate was low. Thus, the study was not sufficiently powered to find actual equivalence between the two groups. Secondly, the presence of osteoporosis of the tibial plateau was not objectively quantified. Thirdly, the addition of a control group involving internal fixation would have been of value. A prospectively designed study comparing internal and circular external fixation of tibial plateau fractures in the elderly could possibly shed further light on the role of circular external fixation in these challenging fractures. 


\section{Conclusion}

Circular external fixation may be a viable treatment option in patients over the age 55 years who sustain high-energy tibial plateau fractures associated with significant soft tissue compromise. No significant difference was found in the union rate or the development of complications when compared to younger patients.

\section{Ethical statement}

All procedures were in accordance with the ethical standards of the responsible committee on human experimentation (institutional and national) and with the Helsinki Declaration of 1975 , as revised in 2008. Prior to commencement of the study ethical approval was obtained from relevant ethical review board. Due to the retrospective nature of the analysis informed written consent was not required.

\section{References}

1. Narayan B, Harris C, Nayagam S. Treatment of high-energy tibial plateau fractures. Strat Traum Limb Recon 2006;1:18-28.

2. Ferreira N, Marais LC. Bicondylar tibial plateau fractures treated with fine wire circular external fixation. Strat Traum Limb Recon 2014:9: 25-32.

3. Papagelopoulos PJ, Partsinevelos AA, Themistocleous GS, Mavrogenis AF, Korres DS, Soucacos PN. Complications after tibial plateau fracture surgery. Injury, Int J Care Injured 2006;37:475-84.

4. Barei DP, Nork SE, Mills WJ, Bradford Henley M, Benirschke SK. Complications associated with internal fixation of high-energy bicondylar tibial plateau fractures utilizing a two-incision technique. $J$ Orthop Trauma 2004:18:649-57.

5. Zura RD, Browne JA, Black MD, Olsen SA. Current management of high-energy tibial plateau fractures. Current Orthopaedics 2007;21:229-35.

6. Musahl V, Tarkin I, Kobbe P, Tzioupis C, Siska PA, Pape H-C. New trends and techniques in open reduction and internal fixation of fractures of the tibial plateau. J Bone Joint Surg [Br] 2009;91-B: 426-33.

7. Colligne C, Sanders R, DiPasquale T. Treatment of complex periarticular fractures using percutaneous techniques. Clin Orthop Relat Res 2000;375:69-77.

8. The Canadian Orthopaedic Trauma Society. Open reduction and internal fixation compared with circular fixator application for bicondylar tibial plateau fractures. Results of a multicenter, prospective, randomized clinical trial. J Bone Joint Surg 2006;88:2613-23.

9. Su EP, Westrich GH, Rana AJ, Kapoor K, Helfet DL. Operative treatment of tibial plateau fractures in patients older than 55 years. Clin Orthop Relat Res 2004;421:240-48.

10. Khodadadyan-Klostermann C, von Seebach M, Taylor WR, Duda GN, Haas NP. Distribution of bone mineral density with age and gender in the proximal tibia. Clinical Biomechanics 2004;19:370-76.

11. Ali AM, El-Shafie M, Willet KM. Failure of fixation of tibial plateau fractures. J Orthop Trauma 2002;16(5):323-29.

12. Schatzker J, McBroom R, Bruce D. The tibial plateau fracture. The Toronto experience 1968-1975. Clin Orthop 1979:139:94-104.

13. Hohl M, Moore TM. Articular fractures of the proximal tibia. In Evarts $\mathrm{CM}$, editor. Surgery of the musculoskeletal system. $2^{\text {nd }}$ ed. New York: Churchill Livingstone; 1990.

14. Oestern HJ, Tscherne H. Physiopathology and classification of soft tissue lesion. Hefte Unfallheilkd 1983;162:1-10.

15. Checketts RG, MacEachern AG, Otterburn M. Pin track infection and the principles of pin site care. In De Bastiani A, Graham Apley A, Goldberg A, editors. Orthofix external fixation in trauma and orthopeadics. Berlin Heidelberg New York: Springer; 2000.

16. Biyani A, Reddy NS, Chaudhury J, Simison AJM, Klenerman L. The result of surgical management of displaced tibial plateau fractures in elderly. Injury 1995;26(5): 291-97.

17. Frattini M, Vaienti E, Soncini G, Pogliacomi F. Tibial plateau fractures in elderly patients. Musculoskelet Surg 2009;93:109-14.

18. Delamarter R, Hohl M and Hopp Jr E. Ligament injuries associated with tibial plateau fractures. Clin Orthop Rel Res1990;250:226.
19. Stevens DG, Beharry R, McKee MD, et al. The long-term functional outcome of operatively treated tibial plateau fractures. $J$ Orthop Trauma 2001;15:312-20.

20. Schwartsman R, Brinker MR, Beaver R, et al. Patient self assessment of tibial plateau fractures in 40 older adults. Am J Orthop 1998;27: 512-19.

21. Hsu C, Chang W, Wong C. Surgical treatment of tibial plateau fracture in elderly patients. Arch Othop Traum Surg 2001;121:67-70.

22. Shimizu T, Sawaguchi T, Skagoshi D, Goshima K, Shigemoto K, Hatsuchi Y. Geriatric tibial plateau fractures: Clinical features and surgical outcomes. J Orthop Science 2016;21:68-73.

23. Roerdink WH, Oskam J, Vierhout PAM. Arthroscopically Assisted Osteosynthesis of Tibial Plateau Fractures in Patients Older Than 55 Years. Arthroscopy 2001;17(8):826-31.

24. Pizanis A, Garcia P, Pohleman T, Burkhardt M. Balloon Tibioplasty: A Useful Tool for Reduction of Tibial Plateau Depression Fractures. J Orthop Trauma 2012;26:e88-e93.

25. Garnavos C, Nikolaos G, Lasanianos G. The management of complex fractures of the proximal tibia with minimal intra-articular impaction in fragility patients using intramedullary nailing and compression bolts. Injury 2011;42:1066-72.

26. Vermiere J, Scheelinck T. Early primary total knee replacement for complex proximal tibia fracturesin elderly and osteoarthritic patients. Acta Orthop Belg 2010;76:785-93.

27. Hsu JE, Pappas N, Lee G-C. A systematic approach to simultaneous periarticular fracture fixation and primary non-hinged knee replacement in patients with comminuted periarticular fractures about the knee. Curr Orthop Prac 2011;22(6):567-72.

28. Watson MA, Mathias KJ, Maffulli N. External ring fixators: An overview. Proc Instn Mech Engrs 2011;214:459-70.

29. Erhan Y, Oktay B, Lokman K, Nurettin A, Erhan S. Mechanical performance of hybrid llizarov external fixator in comparison with llizarov circular external fixator. Clin Biomech 2003;18:518-22.

30. Pugh KJ, Wolinsky PR, Dawson JM, Stahlman GC. The biomechanics of hybrid external fixation. J Orthop Trauma 1999;13:20-26.

31. Khalily C, Voor MJ, Seligson D. Fracture site motion with llizarov and 'hybrid' external fixation. J Orthop Trauma 1998;12:21-26.

32. Parameswaran AD, Roberts CS, Seligson D, Voor M. Pin track infection with contemporary external fixation: how much of a problem? J Orthop Trauma 2003;17:503-507

33. Marsh JL, Smith ST, Do TT. External fixation and limited internal fixation for complex fractures of the tibial plateau. J Bone Joint Surg Am 1995;77(5):661-73.

34. Ali AM, Burton M, Hashmi M, Saleh M. Treatment of Displaced Bicondylar Tibial Plateau Fractures (OTA-41C2\&3) in Patients Older Than 60 Years of Age. J Orthop Trauma 2003;17(5):346-52.

35. Fragomen AT, Rozbruch SR. The mechanics of external fixation. HSS J. 2007;3(1):13-29. 